\title{
REFORMA AGRÁRIA E TURISMO: PRIMEIRAS APROXIMAÇÕES TEÓRICO-CRÍTICAS ${ }^{1}$
}

\author{
REFORMA AGRARIA Y TURISMO: PRIMEROS ACERCAMIENTOS \\ TEÓRICOS Y CRÍTICOS
}

\section{AGRARIAN REFORM AND TOURISM: FIRST CRITICAL-THEORETICAL APPROACHOES}

\author{
Thiago Sebastiano de Melo \\ Universidade Estadual Paulista/Rio Claro \\ thiagomelo13@yahoo.com.br \\ José Gilberto de Souza \\ Universidade Estadual Paulista/Rio Claro \\ jgilbert@rc.unesp.br
}

\begin{abstract}
Resumo: O turismo vem sendo pautado como atividade alternativa para $o$ "desenvolvimento" e a sustentabilidade econômica dos assentamentos e das pequenas unidades de produção familiar. Sendo assim, coloca-se de forma imperiosa refletir quais lógicas fundamentam esta alternativa e em que medida se contrapõe ou corrobora o projeto político da Reforma Agrária, ultrapassando uma perspectiva mais imediata do turismo como setor, atividade econômica e ou forma de geração de renda. Considerando a complexidade de conceitos que se acercam e tergiversações que são tomadas como questões de fundo neste trabalho se objetiva discutir elementos teórico-críticos que se amalgamam ao turismo nos espaços de Reforma Agrária, considerando a perspectiva capitalista burguesa que se associa a esta atividade e quais são os limites operacionais concretos e possibilidades de releitura quando, em verdade nestas aproximações, não se evidenciam antíteses em relação ao projeto político dos movimentos sociais. Desta forma as mediações possíveis entre Turismo e Reforma Agrária devem ser sustentadas nos elementos teórico-críticos que integram esta análise e se consubstanciam em trabalho, reprodução social, ideologia e valor como essencialidades humanas e que determinam as relações sociais.
\end{abstract}

Palavras-chave: Turismo, Mercadoria, Reforma Agrária, Território, Assentamentos.

Resumen: El turismo parece ser una actividad alternativa para el "desarrollo" y la sostenibilidad económica de los asentamientos y pequeñas unidades de producción familiar. Por lo tanto, es importante reflexionar que visión del mundo es compatible con esta alternativa y en qué medida apoya o se opone al proyecto político de la Reforma Agraria, superando una perspectiva más inmediata del turismo como un sector, la actividad económica o la forma de generación de ingresos. Teniendo en cuenta la complejidad de los conceptos utilizados y las superficialidades que aparecen como cuestiones de fondo, este trabajo tiene como objetivo discutir los elementos teóricos y críticos que se mezclan entre el turismo y los espacios de la Reforma Agraria, teniendo

\footnotetext{
${ }^{1}$ Este texto sustenta-se nas concepções de George Lukács (1978) Ontologia do Ser Social: os princípios ontológicos fundamentais de Marx
} 
en cuenta la perspectiva capitalista burguesa que se asocia a esta actividad y cuáles son los límites de las operaciones y las posibilidades de la relectura. De hecho, considerar si estos métodos no son pruebas antitéticas en relación al proyecto político de los movimientos sociales. Así, las mediaciones posibles entre el turismo y la Reforma Agraria deben ser apoyadas en elementos teóricos y críticos que componen este análisis e se recogen en el trabajo, la reproducción social, la ideología y el valor como esencia que determinan las relaciones humanas y sociales.

Palabras-clave: Turismo, Mercancías, Reforma Agraria, Territorio, Assentamiento.

Abstract: Tourism as na activity has been based alternative to the "development" and economic sustainability of settlements and small family production units. Thus, there is so compelling logic which reflect underlyng this alternative and to what extent it supports or opposes the political project of Agrarian Reform, by passing a more immediate prospect of tourism as a sector, economic activity or form of income generation. Considering the complexity of concepts that are quibbling about and that are taken as fundamental issues in this paper aims to discuss theoretical and critical elements that merge to tourism in the areas of agrarian reform, condidering the perspective of bourgeois capitalist that is associated with this activity and what are the concrete operational limits and possibilities of re-reading when in fact these approaches, there are evident antithesis in relation to the political project of social movements. Thus the possible mediations between tourism and agrarian reform must be sustained in the theoretical and critical elementes that make up this analysis and are embodied in work, social reproduction and ideology and value as essentially human and social relations that determine.

Keywords: Tourism, Merchandise, Agrarian Reform, Territory

\section{INTRODUÇÃO}

Notadamente o campo passa por um processo de dinamização econômica pautado não apenas pelos grandes complexos setoriais do agronegócio, mas também porque atinge determinados segmentos sócio-produtivos de menor escala. Noções como "pluriatividade" e "multifuncionalidade" buscam entender/explicar esse "novo rural" que se conforma e que muitas vezes obscurece um movimento latente de concentração fundiária e renda, de alteração da matriz produtiva e homogeneização territorial como lógicas intrínsecas do capital monopolista no campo (SOUZA, 2010), que, conjuntamente, altera as formas de relação campo-cidade e rural e urbano.

Este complexo conjunto de estruturas e processos, que compõem uma realidade agrária e agrícola brasileira e mundial, pauta os estudos da Geografia Agrária, elevando e construindo métodos e categorias de análise que objetivam reconhecer singularidades e homogeneidades e expressam visões sociais de mundo (e de classe) (FERREIRA, 
2001; CAMPOS, FERNANDES，2011; SAQUET, SUZUKI, MARAFON，2011; FABRINI, 2011).

Dentre os novos processos que emergem no campo, o turismo vem sendo pautado como atividade alternativa para o "desenvolvimento" e sustentabilidade econômica dos assentamentos e das pequenas unidades de produção familiar (MOURA, $2005)^{2}$. Sendo assim, coloca-se de forma imperiosa refletir quais lógicas fundamentam esta alternativa e em que medida se contrapõem ou corroboram o projeto político da Reforma Agrária, ultrapassando uma perspectiva mais imediata do turismo como setor, atividade econômica e ou forma de geração de renda.

O Turismo tem sido definido como fenômeno social, que guarda sua gênese na Antiguidade, mas que, entretanto, ganha sentido e potência (fetichizante) na sociedade contemporânea (ALFREDO, 2001; OURIQUES, 2005). Como materialidade, pode-se entender a atividade como o deslocamento pelo espaço, tendo como principal referência as atividades de lazer e entretenimento; mas não só (como se pode observar pelos segmentos: "turismo de negócio", "turismo de saúde", entre outros). Há de se lembrar de análises econômico-setoriais que enxergam a existência de uma cadeia produtiva da atividade. Uma cadeia composta por "agentes" criados exclusivamente para tal fim (como agências, hotéis, etc.) e pela chamada infraestrutura básica, como é o caso da rede hospitalar, de segurança, transporte, água, esgoto, entre outros (LAGE, MILONE, 2001).

De outra forma particularizam-se as ações econômicas das atividades que compõem o trade turístico consolidando uma perspectiva de unidade territorial e produtiva e que demanda, segundo os agentes, estratégias de governança territorial, como é o caso do Turismo no Espaço Rural, que tem sido tomado como um conceito "guarda-chuva", amplo, que abarca as definições mais específicas das atividades ocorridas nesse meio, como turismo rural, ecoturismo, agroturismo, turismo verde, turismo no campo, entre outras (OURIQUES, 2005).

Considerando a complexidade de conceitos que se acercam e tergiversações que são tomadas como questões de fundo, neste trabalho se objetiva discutir elementos

\footnotetext{
${ }^{2}$ Importante ressaltar que o próprio Movimento dos Trabalhadores Rurais Sem Terra - MST já teve um projeto próprio no sul do País nesse sentido, com a proposta de levar turistas para dentro dos assentamentos de forma sistematizada. Essa experiência recebeu o nome à época de MSTur.
} 
teórico-críticos que se amalgamam ao turismo na espacialidade da Reforma Agrária. Considera-se a perspectiva capitalista burguesa que se associa a esta atividade e quais são os limites operacionais concretos e possibilidades de releitura quando, em verdade nesta aproximação, não se evidenciam muitas questões que estão em jogo. Particularmente estas reflexões, considerando a complexidade e a heterogeneidade dos movimentos sociais do campo, se remetem as experiências e reflexões levadas a cabo pelo Movimento dos Trabalhadores Rurais Sem-Terra (MST). Cabe-nos, portanto, reconhecer que nas mutáveis condições da vida humana é imprescindível perseguir a descoberta do desconhecido, no sentido de torná-lo potencializador da práxis-humana (LUKACS, 1979). Está é a lógica que nos remete ao próprio discurso do movimento social (MST) quando questionado sobre as mediações possíveis entre Turismo e Reforma Agrária ${ }^{3}$. Desta forma, parte-se de uma concepção de que estas mediações devem ser sustentadas em elementos teórico-críticos que se consubstanciam em trabalho, reprodução social, ideologia e valor.

Nesta perspectiva, elegemos conceitos que integram em amplitude e profundidade as práticas sócio-espaciais do campo, aproximando nossas reflexões como contribuição ao Movimento social de luta pela terra, que tem reconhecido a importância de refletir sobre turismo enquanto ferramenta tática.

O turismo, hoje, é percebido pelo Movimento como a oportunidade de dar visibilidade às problemáticas enfrentadas na luta pela Reforma Agrária. O MST, por exemplo, reconhece que, diante de um modelo de organização social perverso e de agricultura insustentável, a organização dos trabalhadores do/no campo, atrai olhares "turísticos", para além da mera contemplação da paisagem (MELO, 2009). É óbvio que existe consciência, por parte do Movimento Social, de que há também quem busque os assentamentos visando apenas viver experiências diferenciadas em relação a aquelas obtidas na cidade, mas não é isso que o Movimento busca incentivar, tampouco seu

\footnotetext{
${ }^{3}$ Esta afirmativa se fundamenta não apenas pelas lógicas capitalistas que integram os espaços rurais nas atividades turísticas, mas também pelo próprio reconhecimento do movimento social que tais atividades precisam ser pautadas e refletidas dentro do movimento. Esta preocupação nos foi evidenciada em duas oportunidades por uma das lideranças do MST na região do Pontal do Paranapanema, Sr. Cledson Mendes. Na primeira ocasião (entrevista realizada por Thiago Melo no primeiro semestre de 2009 para o Trabalho de Conclusão de Curso) Mendes relatou a necessidade do Movimento pautar a questão do turismo e pensar num uso estratégico dessa atividade. Já na segunda oportunidade (no trabalho de campo do Encontro Nacional de Grupos de Pesquisas - ENGRUP, realizado no primeiro semestre de 2011), Cledson retomou a colocação e foi mais enfático ao afirmar que é preciso tratar o turismo como uma ferramenta tática, que de visibilidade as causas e demandas dos assentados.
} 
propósito é meramente transformar ou conceber os assentamentos como um espaço bucólico do rural, ou de restauração da força de trabalho do capital, mas consolidar como território e territorialidade de resistência e construção de novas relações sociais e de novas relações com a natureza.

Assim, o ponto de partida desta reflexão se concentra na percepção de que a essência humana se estabelece nas relações sociais e este fundamento elege a processualidade histórica como norteadora desta essencialidade, o que representa um devir construído historicamente, rompendo qualquer associação teológico-dependente, como um movimento linear de causa-efeito. Significa dizer que a essencialidade possível do Movimento de luta pela terra se revela na sua organização sócio-espacial, considerando sua determinação concreta em termos de mudança das estruturas de poder marcadas pela propriedade fundiária e pelo capital e o sentido desta mudança se materializa no território. Este processo não se consubstancia em uma relação mimética de causa e efeito, mas de potencialidade, considerando sua objetividade primária enquanto Movimento, sua teleologia, qual seja, a consolidação do modo de produção camponês, outra concepção sobre a terra (natureza) e o resgate de seu valor de uso.

Por sua vez, a mediação desta lógica se estabelece não apenas pelo movimento primeiro de disputa sócio-espacial, que como síntese agregaria por si só um elemento qualitativo ao território, mas sim por considerar as experiências concretas, a processualidade histórica dos sujeitos sociais, na qual necessita diferenciar-se internamente, seja na organização social e produtiva dos assentamentos (território), seja na representação (territorialidade) destes sujeitos sobre o trabalho e a natureza. A capacidade de sistematização desta experiência de luta e conformação territorial, ou seja, a construção objetiva do Sem Terra resulta do elevar "para si" as experiências com o desconhecido. Consolida-se o desvelamento do real intrínseco por meio de uma práxis social concreta do assentado, o que rompe com qualquer perspectiva idealista sobre a consolidação do território da Reforma Agrária a partir de uma simples estratégia burguesa de desapropriação e assentamento isso porque, toma para si a determinação que a experiência/consciência de ser assentado inaugura: uma nova dimensão (conceitual) territorial para o sujeito. 
Neste aspecto, nossa atenção deve estar concentrada para a transformação interno-territorial. Assim é evidente que o que importa não é saber como o intelectual concebe individualmente uma determinada instituição ou categoria [...] o que importa é a concepção (representação) que formula determinado grupo social sobre determinada instituição e categoria, pois somente ela é socialmente eficaz na determinação territorial (SOUZA, 2011, p.10).

Este movimento que não é teórico, é prático-teórico, identifica a consolidação de uma antítese à estrutura da lógica do pensamento liberal burguês de proprietário privado para pensar-se em "não-proprietário-privado" dando amalgama ao corpo teóricoconcreto do "sem-terra", como existência social comum. Essa antítese se coloca também em relação às formas que os homens aparecem nas relações sociais, deixando, portanto, de se constituírem mercadoria, produzindo uma clivagem às imediatas coisificações que se processam quando sujeito-objeto se situam na lógica do mercado. Destaca-se que na órbita do turismo é exatamente essa processualidade (coisificação sujeito-objeto) que procura se impor.

Trata-se, assim, de um movimento muito profundo e diferenciador quando se pensa no conceito de turismo à medida que sua gênese e dinâmica, como prática social hegemônica, pressupõem o consumo. Nesse arcabouço de homogeneização e "estandardização" de lugares e sujeitos trava-se um enfrentamento, enquanto o rural e a produção agrícola são mercadorias, e, no limite, o sujeito "sem-terra" é o exótico ${ }^{4}$, o “observável-consumo", deixando claro que não é esta lógica que deve mediar as relações dos assentados com o exterior. As definições e práticas apontam para uma perspectiva de entendimento do turismo como atividade marcada por uma lógica em que a mercadoria está vinculada não apenas ao material concreto, mas ao consumo de um simbólico (ideologia) e de uma ideia de valor (troca).

A essência da mercadoria-turismo está em um modo de ser burguês que aprisiona todos os sujeitos como desejo (observável-objeto-consumo). Uma teleologia que eleva a essência do ser (as relações sociais como fundamento) à sociabilidade possível, a sociabilidade do capital, uma processualidade histórica que assume tal sociabilidade como essência inevitável em verdade demarcando a essência humana

\footnotetext{
${ }^{4}$ Trata-se aqui especificamente da leitura que os turistas incorporaram em relação aos indígenas e que se reproduz aos favelados do Rio de Janeiro, uma vez que os pacotes turísticos vendidos, sobretudo aos europeus, "incluem" visitas às favelas, conhecimento do tráfico, entre outros atrativos da periferia do capital.
} 
como objeto, como mercadoria, esta última se consagra em substância das relações sociais, negando o sentido de produção e reprodução camponesas. Assim, o que no modo camponês era marginal (a mercadoria) passa a ser centralidade.

Neste ponto é que se consolidam o Trabalho e a Reprodução Social como categorias de entendimento da lógica sócio-espacial do Movimento e que são elementos norteadores de sua consolidação territorial.

\section{TRABALHO E REPRODUÇÃO SOCIAL}

O trabalho consiste na categoria fundante do ser social, ele existe enquanto parte da reprodução e no capitalismo como antítese à representação de centralidade que ocupa a mercadoria nas relações hegemônicas do modo de produção (o valor de troca, a composição orgânica, por exemplos). Significa dizer que necessariamente o trabalho precisa se consubstanciar em elemento central de sociabilidade nos assentamentos e a sua realização deve ser um constructo de práticas sócio-espaciais que produza a antítese ao individualismo e à vinculação da terra como propriedade privada, considerando que "a disputa, a projeção sócio-espacial do capitalismo (campo de luta) não é simplesmente a propriedade, mas as relações sociais e as representações que a "não-propriedadeprivada" pode construir" (SOUZA, 2011, p. 21).

Ao inserir uma nova centralidade nos processos de sociabilidade se consolida uma nova lógica de reprodução social, considerando que o trabalho como realização do sujeito, consubstancia nova mediação entre meios de produção, natureza e existência. Nas considerações de Marx (2004, p. 37) sobre o trabalho no capitalismo tem-se claramente a importância desta nova centralidade: "Se o trabalho é, portanto, uma mercadoria, é então uma mercadoria com as mais infelizes propriedades”. De forma que esta mediação remete sua ação (práxis) para além de um fazer imediato (mercadoria), mas consolidando processualmente nova teleologia que se projeta nas relações sociais e nas suas representações e consubstancia a categoria trabalho como possibilidade de construir um novo sujeito social nos assentamentos. A ausência do desenvolvimento destas forças produtivas que tem como centralidade o trabalho, não permite um novo movimento na história dos sujeitos, não se estabelece concretamente como uma nova 
formação sócio-territorial campesina, uma formação territorial característica, própria, deste sujeito social.

"O território per-si, como expressão concreta da consciência humana sobre o espaço. O território em-si não tem uma essência predeterminada, ele depende de uma característica definidora para-si” (SOUZA, 2011, p. 10).

Esta característica definidora do "para si" é o trabalho, que altera tanto a produção do indivíduo, quanto altera sua reprodução social Esta característica definidora se coloca como totalidade e imprime ao território esta mesma condição. Considerando o trabalho como fundamento do ser, ele é o locus ontológico de criação do novo, como aponta Lukács (1979), e se torna o elemento de maior complexidade na reprodução social campesina.

Esta complexidade de reprodução social no assentamento, assentada no trabalho, se expressa como uma processualidade histórica em que a divisão do trabalho e a cooperação se articulam não pelo viés do produtivismo e de produtividade do trabalho, medida em mercadorias, mas, ainda que lhes sejam intrínsecas, pela construção social do sujeito coletivo, na consolidação do saber-fazer e da busca da autonomia e da alteridade. De forma que embora tenha se tornado jargão comum, a soberania alimentar representa um dos elementos desta processualidade histórica camponesa. Sempre representou.

A complexidade da reprodução social está também assentada em outro elemento: a linguagem. Como construção dos sujeitos, a linguagem é mediadora do processo de conhecimento e relaciona-se às diversas práticas sociais que se estabelecem e, deste processo de conhecimento, emergem novas relações de poder ${ }^{5}$.

Conhecer é uma exigência do trabalho, e as linguagens se consolidam nos mecanismos de aproximação da consciência sobre o território, sobre o ser-em-si, tornando-o para-si. Trata-se de um movimento cognitivo de extrema relevância a ser realizado pelo assentado, pois é este movimento que a luta pela terra deve produzir com a sociedade ${ }^{6}$, colocando elementos do trabalho e da reprodução social campesina como

\footnotetext{
${ }^{5} \mathrm{O}$ que confere significativa importância à mística do Movimento Social

${ }^{6}$ Esta é a lógica que aqui se propõe para o "turismo".
} 
mediadores da lógica do desvelamento do real. Uma dinâmica que também se processa pela linguagem na construção de elementos simbólicos que sejam capazes de consolidar uma identidade territorial, uma identidade do Sem Terra, que se explicita.

A partir da linguagem se produz a identidade territorial e com ela faz todo o sentido afirmar: a) o fortalecimento dos assentamentos de Reforma Agrária é um passo decisivo no caminho para o enfrentamento das atuais políticas neoliberais e de avanço do capital monopolista imposto ao campo brasileiro; b) os assentamentos são espaços em disputa, que podem, ou não, se constituírem em espaços de resistência, não são dados a priori (SOUZA, 2011), mas se realizam a partir do Trabalho e da Reprodução Social destes sujeitos, e c) as experiências de "turismo" devem estar alicerçadas na conformação desta lógica e não em sua negação.

Nesse sentido, destaca-se que os interesses que, a priori, podem ser postos como individuais (ou de uma parcela muito particular da sociedade, neste caso os assentados) são, em verdade, interesses comuns ao conjunto da sociedade brasileira. Com isso, querse dizer que a adoção de outro modelo agropecuário não é de interesse particular dos assentados, bem como não é exclusivamente de interesse destes que a sociedade saiba da premência e (potencial) eficácia da Reforma Agrária na consolidação de um novo processo sócio-político. E a isso cumpre adicionar que não se pensa, aqui, em simples reforma, senão numa reforma (re)estruturante, que permita (crie condições objetivas) para superarmos o atual modelo de organização social, recuperando a hipótese comunista (ZIZEK, 2011).

Pode-se entender que o turismo sempre se apresentou como uma forma específica de reprodução do capital (somente), mas pode-se também entendê-lo como uma forma específica de relação, que, assim sendo, está em disputa tanto quanto as outras, quando se opõe ao modelo do "observável-consumo". Assim, a atividade turística não se vincula a mera oportunidade de emprego e renda. Pautada no trabalho e na forma de reprodução social dos assentamentos, a atividade turística pode surgir como novo componente de sociabilidade, coletiva, exógena e que nega os pressupostos fundantes do capitalismo, sua ideologia e lógica de valor. 


\section{IDEOLOGIA E VALOR}

O segundo conjunto de conceitos refere à ideologia e ao valor. Em primeiro lugar parte-se de uma clareza lukacsciana de que ideologia não representa uma imagem invertida do real, ou sua falsificação. Este pressuposto teórico, como afirma Lessa (1993), seria o argumento central positivista de que a ciência pode ser reveladora da verdade e, portanto, se consolidaria como neutra, Ao desconsiderar os elementos condicionantes histórico-sociais de sua construção.

A ideologia, assim, se inscreve, como salientamos, em uma segunda instância das práticas sociais, que não são concernentes às ações concretas de apropriação e transformação da natureza, como o trabalho, mas são mediadoras dos conflitos que tal prática sócio-espacial produz: conflitos de classe (um dos condicionantes centrais das formas de leitura do mundo). A ciência, sendo apenas uma das possíveis formas de leitura, não está isenta de ideologia.

A ideologia, como mediadora de conflitos sociais, decorre dos mecanismos de apropriação do trabalho e de seu resultado, e pode apresentar, como representação humana sobre a realidade, uma função prático-social de controle. É o que advertiam Marx e Engels em Ideologia Alemã (2001) sobre a função prático-social de determinadas formas de consciência. A ideologia é uma representação social de mundo e como tal incorpora conhecimento e opera sobre outras ações concretas dos homens, inclusive o trabalho; sem tal capacidade operacional não nos seria possível compreender a alienação.

Uma vez que esta mediação responde pelas formas de compreensão das relações sociais de produção, que em sua análise concreta explicita conflitos, a ideologia tem uma função prático-social (objetivação) evidente no capitalismo, qual seja, desalojar o trabalho da centralidade da vida e reprodução social humana e assentar neste lugar a mercadoria, o consumo. O que não representa em nenhum momento uma inversão sócio-representativa do real, ou de sua falsificação, trata-se de uma concretude histórico-teórica de hegemonia e objetivação de uma classe social que se apropria do trabalho e controla a reprodução social humana.

Implica dizer que toda objetivação é uma objetivação de classe, e produz uma ação de séries causais, como um campo de possibilidades, dentre elas a humanização ou 
desumanização do homem e, deste ponto de vista, se inscreve a necessária objetivação do "sem-terra" na consolidação do território da Reforma Agrária, como síntese de negação da subsunção do trabalho e da natureza e, por sua vez, do controle sobre as formas de reprodução humana. Assim, é está a "imagem" que deve estar à frente da "paisagem" do território campesino.

Uma subsunção que resulta na desumanização, ou coisificação, como categoria representativa de um processo que Marx e Engels (2001) denominaram de Entfremdung, alienação, obstáculo ao conhecimento das objetivações de classe, mas que não anula o homem como demiurgo de sua história. Neste aspecto é que o Movimento social se expressa como exemplo concreto da sua capacidade humana de territorializar práticas sócio-espaciais com profunda antiteticidade à lógica capitalista e concretamente desalojar a mercadoria como elemento central de sociabilidade, o que determina uma fragmentação da força e da função prática da ideologia capitalista.

Esta potencialidade é determinada pelo simples fato de que a essência humana, o trabalho, é portadora de um quantum maior de continuidade (processualidade histórica) que o fenomênico (a alienação), a mercadoria, pois se tratam de mediações distintas (TERTULIAN, 2009). A primeira é capaz de sintetizar o valor, em sua gênese de uso e em sua gênese de troca, pois ao mesmo tempo representa reprodução social e relação social. Neste processo é que se inscreve a dimensão do valor. A ideologia objetiva representar uma dimensão de troca que se impõe na lógica da circulação e do consum(ism)o como valor de troca (em um mimetismo de "uso" para "valor utilidade"), fragmentando a processualidade histórica das dinâmicas de reprodução social e das efetivas relações sociais que constituem o trabalho. Esse dado é fundamental para entender a ontologia do ser social nas categorias marxistas.

Efetivamente, a lógica das relações capitalistas se assenta no "espaço sóciotemporal" (circulação) que é, ao mesmo tempo, ruptura e continuidade entre produção e consumo. Este último é que concentra a atenção do turismo. A questão central é que no capitalismo esse "espaço sócio-temporal", monetariamente denominado de circulação, congrega ruptura locacional quando configura espaços de produção e espaços de consumo de formas distintas. Por sua vez, configura continuidade, à medida que se vincula a uma relação social fundamentada em uma centralidade de valor que é a 
mercadoria, esta última sintetizadora de valor de uso e valor de troca, amplificando o segundo, considerando sua realização no mercado.

Desta forma, a Reforma Agrária tem um elemento muito particular de processualidade no jogo de forças da produção e consumo, a terra, e sua efetiva antiteticidade que se estabelece na possibilidade, no âmbito do campesinato, de constituí-la como efetivo valor de uso e de não a submeter como "mercadoria" ou como meio de produção no estatuto do mercado, retirando-a do espaço sócio-temporal do capitalismo, retirando-a da lógica da circulação, tanto quanto sua produção, unificando pelo valor de uso a produção e o consumo, o que pressupõe nova determinação do valor social.

Souza (2008) explicita este movimento de valor de uso e valor de troca ao analisar o comportamento dos preços de terras.

A trajetória dos preços [de terras] em alguns casos, sobretudo sob a lógica da territorialização sucroalcooleira no extremo oeste paulista, é compreendida como fator de "riqueza regional" este é um fator de força imaterial do conceito de valor de troca (da terra) na consolidação de uma perspectiva de "desenvolvimento e progresso". A terra, como natureza, é valorizada na relação estabelecida pela sociedade em seu processo de produção do espaço. Essa natureza incorporada à vida humana, no âmbito de suas necessidades, tem uma denominação em Marx: valor de uso. [...] A terra apropriada no sentido mais geral de satisfação das necessidades humanas. Porém sua concretude histórica, mediada pelas formas de apropriação, como resultado do metabolismo societal do capital, materializa-se em novo conceito, transforma sua natureza interior e é subsumida pelo valor atribuído pelo capital no âmbito das relações de troca. (mercantis). Está completa a mistificação do modo de produção capitalista advertia Marx, terra mercadoria como característica imediata das relações de produção. $\mathrm{O}$ valor de uso se expressando como valor de troca (riqueza social), este é o valor da natureza no capitalismo quando se converte em dinheiro. Numa palavra: renda. Em suas diferentes formas, separadas entre produção e exploração, considerando que no sistema capitalista a natureza [terra] é ainda valorizada não apenas pela sua transformação em mercadoria (valor de troca), mas como meio de produção, valoriza-se pelo produto mercantil a ser gerado. Esta expectativa de ganhos futuros é que explica a velocidade das trajetórias dos preços [...] a lógica de especulação da terra, que promove padrões de ocupação insustentáveis derivados de mudança na orientação econômica de valor (da terra e da produção) que se territorializa, sobretudo nas áreas onde se concentram modos de produção campesina. (SOUZA, 2008, p. 97-98). 
Significa dizer que está em jogo uma representação social concreta da terra e da produção, que, como salientamos, resulta do trabalho e da reprodução social, capaz de produzir território. Assim, a Reforma Agrária, como valor de uso da terra, ocupa uma nova centralidade nas relações sociais, representando para si e para o outro uma ruptura efetiva, uma revolução (ZIZEK, 2011), a questão é saber quanto o "turismo" como sociabilidade permite construir está possibilidade de ruptura.

Está clara, neste sentido, a confusão para a qual Lukács chama atenção sobre a aproximação de forma inepta entre ser e valor. O valor não é uma externalidade das relações humanas, um produto, mas uma categoria objetiva e tem sua gênese na relação. O valor professa teleologias e causalidades e se desenvolve objetivamente em um elevado grau de universalidades distintas a depender de qual valor se trata: de uso ou de troca (LUKÁCS, 1979).

A compreensão lukácsiana determina, portanto, que na Reforma Agrária "a terra como propriedade privada cinge um valor monetário (troca) e cinde dimensões subjetivas camponesas" (SOUZA, 2011, p.21), ou seja, atinge para a produção (reprodução social e relações sociais) o mesmo estatuto de mercadoria e se revela em negação à subjetividade do Sem Terra.

O Turismo como prática de "consumo" pelo olhar ou pela apropriação das mercadorias, consome o lócus das relações sociais, "sem perceber" consome os sentidos de valor que estão postos, considerando que sua dimensão é única: valor de troca, no campo, sintetizados como unitariedade e complexidade deste consumo que anula a singularidade da Reforma Agrária. Neste caso não há o "hiato”, o espaço sócio-temporal entre produção-consumo e tudo se concretiza mercadoria: o sem terra e o queijo, a farinha e a brisa, a sombra e a prosa. Homogeneização e estandardização do olhar "sem conhecer".

Segundo Lukács, "evidencia-se rapidamente que o ponto de vista da valoração não surge, nesse caso, da essência da coisa [do campesinato] que, ao contrário, ela é arbitrariamente escolhida e aplicada do exterior sobre uma matéria" (LUKÁCS, 1979, p.16). Esta processualidade objetiva de valoração conduz a causalidades ao mesmo tempo não valorativas, pois suprime sujeito e sua concretude histórica pelo "olhar superficial de consumo do outro", submetendo uma matéria heterogênea ao "valor" de troca, um sentido arbitrariamente escolhido, de modo puramente ideal, para quem terra e camponês são 
absolutamente estranhos (alienação). Nesta processualidade opera-se uma homogeneização lógico-abstrata desta essência heterogênea ("sem-terra"), deformando sua representação de modo a encaixá-la em um sistema logicamente estandardizado e deduzido do "observável-consumo". Transforma-se tudo em mercadoria.

Este nível de abstração concreta da atividade prática do turismo que implica em uma aproximação que não constitui objetivamente a totalidade do outro, mas uma totalidade autocentrada (em-si), caracteriza uma esfera gnosiológica, com uma processualidade e mediação puramente estranha, ideologizada.

Ainda que se reconheça que a convivência com o desconhecido é uma determinação ineliminável do mundo dos homens, é preciso conceber que esta determinação pode se estabelecer mediada por elementos concretos que alteram a objetividade dos sujeitos no mundo e, desta forma, altera a relação entre os homens - e suas formas de representação, a ideologia (LUKÁCS, 1979). A Reforma Agrária como espaço social do turismo só pode alterar tal objetividade quando estabelece outra relação, cuja centralidade não seja a mercadoria, mas desvelando concretamente sua experiência de construção territorial mediada pela centralidade do trabalho, da natureza e da alteridade dos sujeitos. Para Lukács, o real não deve ser deduzido de um conceito abstrato, antes, as abstrações da consciência apenas possuem significados à medida que refletem a essência do próprio real, ou seja, quando altera as relações entre os homens (LUKÁCS, 1979).

Para o Sem Terra, concretamente, a relação com o desconhecido, a consolidação territorial do assentamento, se estabeleceu determinada pelas necessidades objetivas, apreciações e possibilidades que predominaram historicamente em cada situação de acampamento, ocupação e assentamento. Esta processualidade produz uma distinção qualitativa entre o desconhecido e o conhecido, e, disso, decorre uma sistematização do acúmulo de elementos cognitivos (experiências e reflexões) frente ao desconhecido na consolidação do território da Reforma Agrária, mas que pode se perder no olhar ideologizado do outro.

Por sua vez, não se trata aqui de esconder-se, ao contrário, cabe ao Sem Terra nas mutáveis condições da vida social (o turismo é uma delas) auxiliar na descoberta do desconhecido para o outro, sem subverter sua essencialidade, sua processualidade histórica. A questão é como construir uma experiência por meio da qual seja possível 
“avizinhar-se" desse território, consolidá-lo para além do em-si, consolidá-lo para-si, como existência social. Estas representações são capazes de refletir na consciência as determinações subjetivas do Sem Terra como dimensão concreta no "turismo no espaço rural"?

Evidentemente consideramos que sim. O contrário seria uma negação da processualidade histórica e da determinação humana. A forma de uma representação imediata, completamente ausente de determinações concretas do território, não rompe com a imediaticidade do consumo, paralisante. O Sem Terra precisa se consolidar como desconhecido para consolidar elementos que pertençam a uma esfera de conhecimento possível e singular. Apenas assim o outro poderá em um trabalho de "aproximação" conhecer esta totalidade real (VIGOTSKI, 1998). Entre o processo gnosiológico e o processo real, objetivo, há uma relação insuperável entre o que é refletido (o ente em-si) e o reflexo que vem a ser pela atividade da consciência, enquanto atividade da consciência (para-si), e esse reflexo pode ser tudo, menos fotográfico ${ }^{i}$ (LUKÁCS, 1979).

Não se trata em absoluto de uma identidade sujeito-objeto, como um mimetismo que o outro incorpora a subjetividade do Sem Terra, mas efetivamente de uma relação social que incorpora elementos concretos da processualidade histórica de sua construção como sujeito e da consolidação de seu território, enquanto práxis. O turismo deveria se chamar assim "vivência". Temos como ilustração desse pensamento, as experiências do Estágio Interdisciplinar de Vivência - EIV, que ocorrem em diversos assentamentos.

Trata-se de uma experiência na qual, a partir de um território consolidado, pode-se apreender outra concepção de mundo, outra perspectiva nas relações sociais, o que pode, ou não, criar o estranhamento com a organização social hegemônica. Assim, não é o caso de afirmar que o turismo em assentamentos de Reforma Agrária (nos territórios construídos a partir de uma perspectiva não-capitalista) seja a receita/solução única e infalível para a superação da alienação predominante. Antes, é encará-lo como mais uma instância de enfrentamento e estranhamento que enseja o deslocamento da zona de conforto do turista, efetivamente evitando que se acrescente uma dimensão representativa da realidade que seja diametralmente oposta ao que se propõe.

Em outras palavras, não permitir a observação do Movimento como se fosse a "poltrona Airborne", se este pretende, de fato, conceber aquele território como legítimo, uma ruptura à práxis do consumo (BAUDRILLARD, 2004). Dessa forma, não é a 
mercadoria que pauta esse encontro. Não é o espetáculo que costura e dá margem às relações, pensadas e vivenciadas. A produção agrícola camponesa e os artesanatos vendidos não são meros souvenires, provas da estada naquele espaço/cenário, ao contrário, expressam a materialização de outra concepção de mundo territorializada.

Este conceito responde por nossas preocupações acerca do projeto político da Reforma Agrária que ultrapassa a perspectiva de seu próprio território, mas tem ali sua concretude, consolidação de sua essência (relação social). Sua dinâmica permite compreender como os homens fazem a história, como assumem a construção de seu futuro. Fora desses elementos críticos, trata-se de se expor na vitrine (ou jaula?), quando o espaço da Reforma Agrária deixa de ser território e passa a ser "confinamento", com o peso produtivo-capitalista que a palavra enseja, e representa outra dimensão de valor que nega a essencialidade da luta dos movimentos sociais, no campo e na cidade.

Embora o turismo tenha um grande potencial fetichizante, sendo mesmo um dos principais elementos na dinâmica de reprodução das relações de produção, ele pode cumprir um papel essencial como atividade-tática na consolidação da imagem dos assentamentos de Reforma Agrária. Seja por desmistificar estes espaços, seja por demonstrar a possibilidade de desenvolvimento de territórios não-capitalistas. Para Fabrini “o território camponês é portador de um conjunto de práticas não-capitalistas, como produção de autoconsumo e resistência, controle relativo do processo produtivo, autonomia, relações comunitárias e solidárias, dentre outras" (2011, p. 110). Essas práticas precisam constituir um território não-capitalista, pois essa constituição não se dá exclusivamente por se tratar de um assentamento de Reforma Agrária e sim nas relações e representações sociais que ali se manifestam (território e territorialidade).

\section{CONSIDERAÇÕES FINAIS}

A partir das reflexões expostas, pode-se entender o turismo (pensado nos espaços da Reforma Agrária e em relação a esta) como uma atividade-tática no processo de consolidação de territórios não-capitalistas. Esse binômio (Reforma Agrária e territórios não-capitalistas) constitui-se de elementos de outro projeto de desenvolvimento nacional, sobretudo para o campo. Caracterizando a existência de projetos diferentes em disputa no âmbito da política agrária. É inegável que a Reforma 
Agrária anda a passos lentos e está permeada por interesses outros, que não unicamente o da reestruturação fundiária.

Se até agora a essência da mercadoria-turismo está em um modo de ser burguês que aprisiona todos os sujeitos como desejo (objeto-consumo), a presente reflexão questiona se não é possível pensá-lo na perspectiva de outra teleologia. O turismo não seria, em-si, o elemento constituinte de outra sociabilidade, mas, a partir dela, aqui entendida como a sociabilidade desenvolvida em determinados assentamentos de Reforma Agrária (espaços não-capitalistas), seria mais um componente na dinâmica de alteração das relações sociais de poder. É dizer que não é porque o sujeito está como turista que ele não pode estranhar o que se lhe apresenta.

Para a concepção de turismo aqui proposta, se faz essencial o entendimento dos quatro elementos teórico-críticos, quais sejam: Trabalho, Reprodução Social e Ideologia e Valor. Desta forma, é imperioso que o trabalho tenha centralidade na constituição dos assentamentos de Reforma Agrária, em oposição a centralidade que hoje ocupa a mercadoria. A Reprodução Social ganha outro sentido e pode consolidar a divisão do trabalho e a cooperação na perspectiva da construção social do sujeito, na consolidação do saber-fazer e da busca da autonomia e da alteridade. E nesse sentido, cumpre a reiteração da necessidade do esforço de fragmentar a função social da ideologia, que, tendo como centralidade a mercadoria, valora a terra de forma estranha aos preceitos dos movimentos sociais. Assim, os elementos teórico-críticos possibilitam compreender a constituição de territórios não-capitalistas, e como devem mediar outra forma de sociabilidade (no turismo). 


\section{REFERÊNCIAS BIBLIOGRÁFICAS}

ALFREDO, A. Geografia do Turismo. A crise ecológica como crítica objetiva do trabalho. O turismo como ilusão necessária. Geousp Espaço e Tempo, São Paulo, v. 9, p. 37-62, 2001.

BAUDRILLARD, J. O sistema dos objetos. São Paulo: Perspectiva, 2004.

CAMPOS, J. F. S.; FERNANDES, B. M. O conceito de paradigma na geografia: limites, possibilidades e contribuições para a interpretação da geografia agrária. CAMPO-TERRITÓRIO: revista de geografia agrária, v. 6, n. 11, p. 21-52, fev., 2011.

FABRINI, J. E. Território, classe e movimentos sociais no campo. ANPEGE. vol.7 n. 7. p. 97-112, 2011.

FERREIRA, D. A. O. Geografia agrária no Brasil: conceituação e periodização. Terra Livre. São Paulo. n. 16. 2001. P. 39-70

LAGE, B. H. G.; MILONE, P. C. Economia do turismo. Ed. Atlas. 2001

LESSA, Sergio. Lukács e o marxismo contemporâneo. Temáticas, $n^{\circ} 1-2$, IFCHUnicamp, 1993.

LUKÁCS, György. Ontologia do Ser Social: os princípios ontológicos fundamentais de Marx. São Paulo: Editora Ciências Humanas, 1979.

MARX, Karl; ENGELS, Friendrich. A ideologia alemã. Tradução de Luiz Cláudio de Castro e Costa. $2^{\mathrm{a}}$ ed. São Paulo: Martins Fontes, 2001.

MARX, Karl. Manuscritos econômico-filosóficos. São Paulo: Boi Tempo, 2004.

MELO, T. S. Turismo na perspectiva do MST; turismo em assentamento de Reforma Agrária e outros apontamentos sobre turismo no meio rural. Monografia. Curso de turismo da Universidade Estadual Paulista. Rosana, 2009, $94 \mathrm{f}$.

MOURA, L P. Diagnóstico do potencial turístico dos assentamentos rurais do município de Rosana. Rosana: Campus Experimental de Rosana, 2005. $15 \mathrm{f}$. Projeto de Pesquisa enviado a Fundação de Amparo à Pesquisa do Estado de São Paulo. 2005.

OURIQUES, H. R. A produção do turismo: fetichismo e dependência. Campinas, SP: Editora Alínea, 2005.

SAQUET, M. A.; SUZUKI, J. C.; MARAFON, G. J. (Orgs) Territorialidades e diversidades nos campos e nas cidades latino-americanas e francesas. 1 ed. São Paulo: Outras Expressões, 2011.

SOUZA J. G. Questão de Método: a homogeneização do território rural paulista. Jaboticabal-SP: Unesp. (Tese de Livre Docência). 2008a. 163p.

SOUZA, J.G. A Geografia agrária e seus elementos de crítica sobre o avanço do capital monopolista no campo brasileiro. Canadian Journal of Latin American and Caribbean Studies, v. 34, p. 147-176, 2010

SOUZA, J. G. Limites do Território. Agrária (USP). 2011. (pp.1-30 - Prelo). 
TERTULIAN, Nicolas. Uma apresentação à Ontologia do Ser Social de Lukács. Disponível em: http://www.unicamp.br/cemarx/criticamarxista/3Tertulian.pdf Acessado em 2009.

VIGOTSKI, L. S. Pensamento e Linguagem. $2^{\text {a }}$ ed. São Paulo: Martins Fontes, 1998.

ŽIŽEK, S. Primeiro como tragédia, depois como farsa. Trad. Maria Beatriz de Medina. - São Paulo: Boitempo, 2011.

ŽIŽEK, S. Slavoj Zizek e a novidade do comunismo. Disponível em: http://oglobo.globo.com/blogs/prosa/posts/2011/05/28/slavoj-zizek-a-novidadedo-comunismo-382949.asp Acesso em: 01 Jun. 2011. 